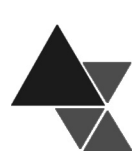

\title{
Características físicas, químicas e sensoriais de doce de manga cremoso acrescido de farinha de okara
}

\author{
Bruno Ricardo de Castro Leite Júnior ${ }^{1}$, Patrícia Martins de Oliveira ${ }^{2}$, Renan Luís Emídio de \\ Castro $^{3}$, Eliane Maurício Furtado Martins ${ }^{4}$, Joaquim Mário Neiva Lamas ${ }^{3}$
}

Este trabalho objetivou elaborar e caracterizar doce de manga cremoso acrescido de farinha de okara. Foram elaboradas três formulações: controle (sem adição de farinha), contendo $1 \%$ e $3 \%$ de farinha de okara. Foram realizadas análises de proteína bruta, extrato etéreo e fibra bruta, na farinha de okara, e pH, acidez, Sólidos Solúveis Totais (SST), proteína, gordura, Atividade de Água (Aw), cor, contagem de bolores e leveduras e análise sensorial, nas formulações de doces. Para os doces elaborados a acidez, Aw e cor ( $L^{*}, a^{*}$ e b*) não diferiram entre as amostras. A amostra contendo $3 \%$ de farinha obteve os maiores valores de $\mathrm{pH}, \mathrm{SST}$, proteína e gordura após a fabricação e após 70 dias de armazenamento. Todas as amostras estavam de acordo com a legislação brasileira para bolores e leveduras. $\mathrm{Na}$ análise sensorial, o atributo cor não diferiu entre as amostras controle e as contendo $1 \%$ e $3 \%$ de farinha. Para aroma, textura, sabor, impressão global e intenção de compra as amostras controle e adicionada de 1\% não diferiram entre si, e apresentaram médias superiores à amostra contendo 3\% de okara. Os produtos elaborados obtiveram alto valor nutricional e boa aceitação.

Palavras-chave: aceitabilidade, doce em pasta, novos produtos, resíduo de soja.

\section{Physical, chemical and sensory properties of sweet creamy mango containing okara's flour}

This study aimed to develop and characterize sweet mango cream plus okara flour. Three formulations were prepared: control (no addition of flour), containing 1\% and 3\% flour okara. Analyses were performed using crude protein, ether extract and crude fiber in okara flour, and $\mathrm{pH}$, acidity, Soluble Solids (TSS), protein, fat, Water Activity (Aw), color, mold count and yeast and sensory analysis, the formulations of candy. The okara flour had a protein content of $26.19 \%$, fat content of $11.35 \%$ and $13.13 \%$ fiber. For sweets elaborate, acidity, Aw and objective color $\left(\mathrm{L}^{*}, \mathrm{a} *\right.$ and $\mathrm{b} *$ ) did not differ between samples. The sample containing $3 \%$ flour obtained the highest values of $\mathrm{pH}$, TSS, protein and fat after manufacture and after 70 days of storage. All samples were in accordance with Brazilian law for molds and yeasts. In sensory analysis, the color attribute did not differ between control and samples containing 1\% and 3\% okara flour. For flavor, texture, taste, overall impression and

\footnotetext{
1 Universidade Estadual de Campinas (UNICAMP), Faculdade de Engenharia de Alimentos (FEA), Departamentos de Tecnologia de Alimentos, Campinas, SP.

${ }^{2}$ Universidade Federal de Viçosa (UFV), Departamento de Tecnologia de Alimentos (DTA), Viçosa, MG.

${ }^{3}$ IF Sudeste MG, Departamento de Ciência e Tecnologia de Alimentos (DCTA), Rio Pomba, MG. Correspondência: Instituto Federal de Educação, Ciência e Tecnologia do Sudeste de Minas Gerais (IF Sudeste MG), Departamento de Ciência e Tecnologia de Alimentos (DCTA), Rio Pomba, MG. Av. Dr. José Sebastião da Paixão s/no, Bairro Lindo Vale, Rio Pomba, MG. CEP 36180-000. Tel. (32)3571-5700. E-mail: eliane.martins@ifsudestemg.edu.br.

${ }^{4}$ Instituto Federal de Educação, Ciência e Tecnologia do Sudeste de Minas Gerais (IF Sudeste MG), Departamento de Ciência e Tecnologia de Alimentos (DCTA), Rio Pomba, MG.
} 
purchase intent was observed that the control samples and increased by $1 \%$ did not differ, and had means higher than the sample containing $3 \%$ of okara. The elaborated products had a high nutritional value and good acceptance.

Key-words: acceptability, sweet in paste, new products, soybean residue.

\section{INTRODUÇÃO}

A manga (Mangifera indica L.) destaca-se entre as frutas tropicais de maior expressão econômica nos mercados brasileiro e internacional [1,2]. A Índia é o maior produtor mundial com $40,37 \%$ do total, quase quatro vezes maior que a China $(11,22 \%)$, que é a segunda colocada. O Brasil ocupa a sétima posição, com uma produção de 1,5 milhões de toneladas $(4,62 \%$ do total) [3]. No entanto, é importante destacar que a produtividade brasileira é bem superior aos demais grandes produtores sendo de $17 \%$ contra $6 \%$ da Índia e $8 \%$ da China [3]. Além disso, a manga apresenta grande quantidade de polpa, aroma e cor muito agradáveis, possui aparência exótica constituindo rica fonte de carotenoides e carboidratos [1,4]. É uma fruta climatérica que apresenta respiração celular intensa após ser colhida e, com isso, sua deterioração é mais rápida, o que dificulta a comercialização de toda a safra da fruta in natura, sendo a industrialização uma alternativa para o excedente de produção, além de possibilitar o consumo da fruta na entressafra [5].

Os doces em pasta são resultantes do processamento adequado das partes comestíveis dos vegetais, adicionados de açúcares, água, podendo ou não ser adicionados de pectina $(0,5$ a $1,5 \%$ em relação à polpa), ajustador de pH (ácido cítrico), além de outros ingredientes e aditivos permitidos pela legislação brasileira até alcançar a consistência adequada, assegurando estabilidade ao produto. Após o processamento, os doces devem ser devidamente embalados e armazenados a temperatura ambiente [6-9].

Do ponto de vista microbiológico, os doces artesanais, conforme a embalagem e condições de processamento e armazenamento, têm uma vida útil que pode variar de 6 meses a 1 ano [10], a qual pode ser prolongada pela adição de ácido sórbico e seus sais, que têm boa atuação na faixa de $\mathrm{pH}$ de 4,0 a 6,0 [11]. Assim, a elaboração de doces, em geral, é uma das formas empregadas para a conservação de frutas, pois além do tratamento térmico, é adicionado açúcar que promove o aumento de sua concentração, alterando a pressão osmótica, reduzindo a atividade de água e consequentemente aumentando a vida útil do produto.

As frutas, de forma geral, são pobres em proteínas de alto valor biológico. A soja, por sua vez, possui grande quantidade de aminoácidos essenciais como lisina, triptofano e isoleucina [12]. O resíduo de okara é um subproduto do processamento do extrato aquoso de soja e do tofu e contém aproximadamente $42 \%$ de proteína (base seca) com boa qualidade nutricional [13], sendo considerado uma fonte vegetal de baixo custo com potencial para o consumo humano [14,15]. Cerca de 1,1 kg de okara fresco (base úmida) é produzido pelo processamento de $1 \mathrm{~kg}$ de grãos de soja mais quantidade padrão de água, para obtenção do extrato aquoso; e da desidratação de $1 \mathrm{~kg}$ deste subproduto, são obtidos aproximadamente $250 \mathrm{~g}$ de okara seco (farinha) [16].

A utilização da soja em alimentos tradicionais tem aumentado. Segundo a Food and Drug Administration (FDA) e a Agência Nacional de Vigilância Sanitária (ANVISA), a ingestão de $25 \mathrm{~g}$ de proteína de soja por dia, associada a uma dieta com pouca gordura saturada e colesterol, pode reduzir o risco de doenças cardíacas [13]. Alimentos com soja contêm proteínas que reduzem o nível de Lipoproteína de Baixa Densidade (Low Density Lipoprotein - LDL; colesterol ruim) e aumentam o nível de Lipoproteína de Alta Densidade (High Density Lipoprotein - HDL; colesterol bom), além disso, sua adição permite redução dos custos sobre o produto final. Jackson et al. ${ }^{[17]}$ concluíram que aproximadamente um terço do conteúdo de isoflavonas da soja é transferida ao okara. Em razão da concentração protéica deste ser semelhante a dos grãos de soja, o okara apresenta um grande potencial para ser utilizado como fonte de nutrientes e isoflavonas em produtos alimentícios.

É de extrema importância a avaliação da qualidade sensorial das amostras experimentais antes de sua comercialização. Desta forma, a determinação da 
aceitação de um produto é parte crucial no processo de desenvolvimento ou melhoramento de produtos [18]. Assim, este trabalho objetivou elaborar, caracterizar e analisar sensorialmente o doce de manga cremoso acrescido de farinha de okara.

\section{MATERIAL E MÉTODOS}

O experimento foi realizado na Unidade de Processamento de Frutas e Hortaliças e nos laboratórios de físico-química, microbiologia e análise sensorial do Instituto Federal de Educação, Ciência e Tecnologia do Sudeste de Minas Gerais (IF Sudeste MG), Campus Rio Pomba no período de junho a dezembro de 2011.

\section{Obtenção da farinha de okara}

Para obtenção do okara, primeiramente os grãos foram submetidos à etapa de sanitização para eliminação das sujidades e inativação da microbiota contaminante, em seguida, os grãos de soja foram submetidos ao descascamento em descascador de rolos e macerados em água na proporção de 1:10 por 2 horas à temperatura ambiente. Posteriormente, os grãos foram aquecidos por 5 minutos e submetidos à trituração em liquidificador industrial, em seguida, ainda quente, os grãos foram separados por filtração em peneira de 80 mesh. Logo após, o resíduo foi desidratado em estufa à $105^{\circ} \mathrm{C}$ por 9 horas e triturado em liquidificador para obtenção da farinha de okara (Figura 1).

Figura 1. Fluxograma de processamento para obtenção da farinha de okara

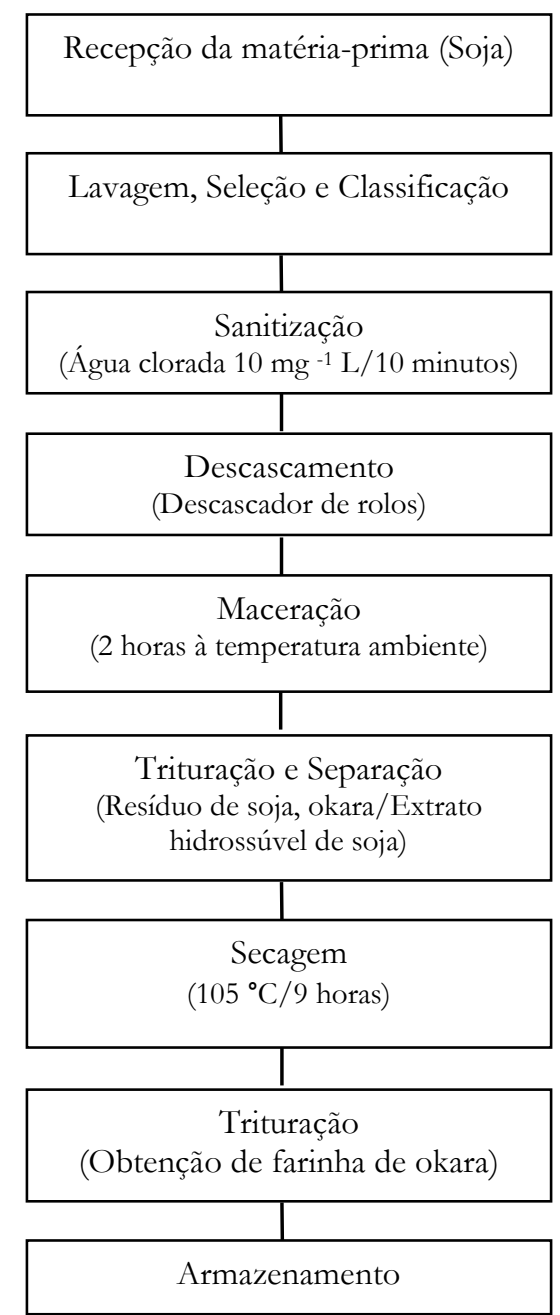




\section{Fabricação do doce de manga}

Cerca de $80 \mathrm{~kg}$ de frutas de manga da variedade Tommy Atkins adquiridas no comércio local previamente selecionadas foram imersas em água clorada (100 mg L-1) por 10 minutos, despolpadas em despolpadeira (Tecnint, Congonhal, Minas Gerais), sendo a polpa transferida para o concentrador à vácuo modelo Buller (Tecnint, Congonhal, Minas Gerais). Em seguida foram adicionados, em relação ao volume (massa) de polpa, $45 \%$ de açúcar e a farinha de okara nas concentrações de $1 \%$ e $3 \%$. O tratamento controle consistiu do doce sem adição de okara. A mistura foi concentrada até $62^{\circ}$ Brix e, logo após, o doce foi transferido ainda quente para embalagens de polietileno de alta densidade, sendo resfriados a temperatura ambiente e armazenados a $10^{\circ} \mathrm{C}$ (Figura 2).

Figura 2. Fluxograma de processamento de doce cremoso de manga adicionado de farinha de okara

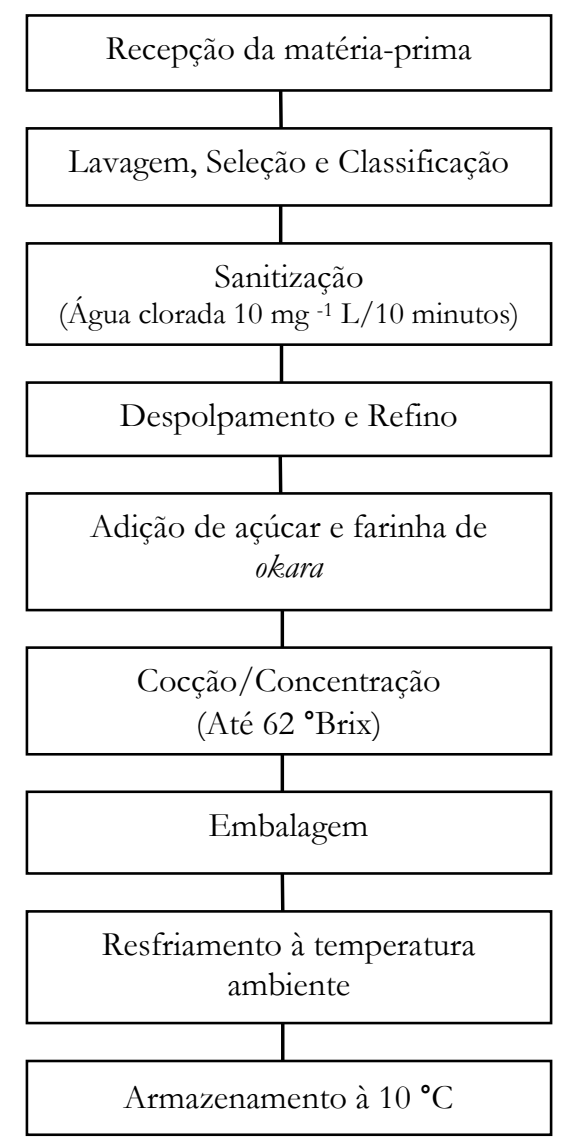

\section{Análises físico-químicas na farinha de okara}

As análises de proteína bruta, extrato etéreo e fibra bruta foram realizadas de acordo com estabelecido pelo manual do Instituto Adolf Lutz [19] em base seca.

\section{Análises físico-químicas nos doces elaborados}

As análises de $\mathrm{pH}$, acidez total titulável $(\%$ ácido cítrico), sólidos solúveis totais ( ${ }^{\circ}$ Brix), proteína, gordura e atividade de água foram realizadas de acordo com as normas do Instituto Adolfo Lutz ${ }^{[19]}$. O produto foi processado em duas repetições, em cada repetição foi realizada as análises em triplicata tanto nos tempos 0 (zero) e após 70 dias de armazenamento a $10^{\circ} \mathrm{C}$ a fim de determinar a vida de prateleira do produto, com 
exceção de proteína e gordura que foram determinadas somente no tempo zero.

\section{Cor objetiva}

A cor objetiva dos doces dos tratamentos controle e acrescido de 1 e $3 \%$ de okara, armazenados a $10{ }^{\circ} \mathrm{C}$, foi avaliada utilizando-se o equipamento MiniScan EZ System (HunterLab, Reston, Virginia, EUA), por meio da leitura direta de reflectância das coordenadas L*, a*, b* empregando a Escala CIELAB (Commission Internationale de L'éclairage $L^{*} a^{*} b^{*}$ ), por ser adotada como padrão pela Comissão Internacional de Iluminação. Para cada amostra foram realizadas três leituras em diferentes pontos da superfície dos produtos a fim de se obter o resultado médio nos tempos 0 (zero) e após 70 dias de armazenamento a 10 ${ }^{\circ} \mathrm{C}$.

\section{Contagem de Bolores e Leveduras}

A contagem de bolores e leveduras por grama de doce cremoso de manga acrescido ou não de farinha de okara foi determinada de acordo com a Instrução Normativa no 62 [20]. As amostras dos tratamentos controle e adicionado de 1 e $3 \%$ de okara foram analisadas nos tempos 0 (zero) e após 70 dias de armazenamento a $10{ }^{\circ} \mathrm{C}$, uma vez que, a avaliação destes micro-organismos são requisitos microbiológicos preconizados pela RDC no 12 da ANVISA, do Ministério da Saúde [21].

\section{Análise sensorial dos doces}

A avaliação da aceitabilidade sensorial das diferentes amostras de doce cremoso de manga foi realizada nas dependências do IF Sudeste MG, Campus Rio Pomba, com 100 julgadores não treinados, utilizando escala hedônica de nove pontos variando de gostei extremamente (9) a desgostei extremamente (1) para os atributos cor, aroma, textura, sabor e impressão global, além da intenção de compra usando a escala estruturada de 5 pontos, na qual, 5 representou a nota máxima "certamente compraria" e, 1 a nota mínima, "certamente não compraria" [18].

\section{Análise estatística}

Os dados obtidos das análises físico-químicas, de determinação de cor e da análise sensorial foram submetidos à Análise de Variância (ANOVA) e ao teste de Tukey $(p<0,05)$, utilizando-se o programa SISVAR, 2007.

\section{RESULTADOS E DISCUSSÃO}

\section{Características físico-químicas da farinha de okara}

Verificou-se que a farinha de okara utilizada na elaboração dos produtos apresentou teores de proteína bruta, extrato etéreo e fibra bruta, da ordem de $26,19 \%$; $11,35 \% ; 13,13 \%$, respectivamente. De acordo com Cavalheiro et al. [22] a farinha de resíduo de soja contém, em base seca, 30,3\% de carboidratos, $28,0 \%$ de proteína, $12,2 \%$ de lipídeos, $16,1 \%$ de fibras e 3,4\% de cinzas; valores estes semelhantes ao determinado neste estudo. No entanto, Cantuária et al. [23] obtiveram teores de proteína $(34,76 \%)$ e de lipídeos $(28,61 \%)$ maior do que observado neste estudo, tal fato pode ser explicado devido estes autores realizarem a etapa de secagem da farinha de okara por prensagem, ao invés de secagem em estufa em temperatura elevada com realizada neste estudo. Hasler [24] afirma que o okara é rico em proteínas de alto valor biológico, possui ótimo perfil de aminoácidos essenciais e alta digestibilidade in vitro. Com isso pode-se observar que a utilização do okara em alimentos aumenta o valor nutricional dos produtos produzidos.

\section{Características físico-químicas dos doces elaborados}

Os doces cremosos elaborados foram analisados quanto a sua composição físico-química, tendo os resultados apresentados na Tabela 1.

Em relação à acidez titulável, observou-se que não houve diferença $(\phi>0,05)$ entre as amostras no tempo zero e após 70 dias de armazenamento, ou seja, a adição da farinha de okara não influenciou na acidez do produto. Para $\mathrm{pH}$, verificou-se que a amostra acrescida de 3\% de okara diferiu das demais $(p<0,05)$ logo após a fabricação dos produtos, no entanto, após 70 dias de armazenamento, não foi verificado diferença entre as amostras $(p>0,05)$. Os valores de $\mathrm{pH}$ estão ligados diretamente ao estágio de maturação da manga. Durante o amadurecimento ocorre diminuição da acidez com consequente aumento do $\mathrm{pH}$, pois os ácidos orgânicos estão entre os constituintes celulares metabolizados durante o processo de estádio de maturação das frutas [25]. O Regulamento Técnico da 
Resolução de Diretoria Colegiada RDC no 272 , de 22 de Setembro de 2005, da ANVISA, fixa os padrões e as características mínimas de qualidade a que devem obedecer estes produtos. Dentre os requisitos apresentados, destaca-se o $\mathrm{pH}$ que deve estar abaixo de 4,5 [26]. Portanto, os produtos estavam de acordo com a legislação vigente.

Tabela 1. Resultados (1) das análises físico-químicas de amostras de doce de manga cremoso e acrescido de farinha de okara

\begin{tabular}{l|c|c|c|c|c|c}
\hline \multirow{2}{*}{ Amostra } & \multicolumn{6}{|c}{ Parâmetros avaliados (t (6) = 0) } \\
\cline { 2 - 7 } & ATT (2) & $\mathbf{p H}$ & SST (3) & Proteína (\%) & Gordura (\%) & Aw (4) \\
\hline Controle & $0,32 \pm 0,01 \mathrm{a}$ & $4,02 \pm 0,01 \mathrm{~b}$ & $63,0 \pm 2,83 \mathrm{~b}$ & $0,28 \pm 0,03 \mathrm{c}$ & $0,17 \pm 0,02 \mathrm{~b}$ & $0,862 \pm 0,02 \mathrm{a}$ \\
1\% okara & $0,33 \pm 0,03 \mathrm{a}$ & $4,08 \pm 0,01 \mathrm{~b}$ & $63,5 \pm 2,12 \mathrm{~b}$ & $0,60 \pm 0,04 \mathrm{~b}$ & $0,23 \pm 0,04 \mathrm{~b}$ & $0,861 \pm 0,02 \mathrm{a}$ \\
$3 \%$ okara & $0,31 \pm 0,05 \mathrm{a}$ & $4,26 \pm 0,11 \mathrm{a}$ & $65,5 \pm 3,54 \mathrm{a}$ & $1,36 \pm 0,02 \mathrm{a}$ & $0,48 \pm 0,03 \mathrm{a}$ & $0,863 \pm 0,02 \mathrm{a}$ \\
DMS (5) & 0,073 & 0,139 & 1,771 & 0,045 & 0,063 & 0,006 \\
\hline
\end{tabular}

\begin{tabular}{c|c|c|c|c|c|c}
\hline \multirow{2}{*}{ Amostra } & \multicolumn{7}{|c}{ Parâmetros avaliados (t (6) = 70 dias) } \\
\cline { 2 - 8 } & ATT (2) & pH & SST (3) & Proteína (\%) & Gordura (\%) & Aw (4) \\
\hline Controle & $0,47 \pm 0,23 \mathrm{a}$ & $4,35 \pm 0,10 \mathrm{a}$ & $69,7 \pm 0,91 \mathrm{~b}$ & ND & ND & $0,861 \pm 0,03 \mathrm{a}$ \\
1\% okara & $0,47 \pm 0,28 \mathrm{a}$ & $4,45 \pm 0,09 \mathrm{a}$ & $70,9 \pm 1,31 \mathrm{ab}$ & ND & ND & $0,859 \pm 0,02 \mathrm{a}$ \\
$3 \%$ okara & $0,47 \pm 0,23 \mathrm{a}$ & $4,43 \pm 0,02 \mathrm{a}$ & $71,6 \pm 1,11 \mathrm{a}$ & ND & ND & $0,848 \pm 0,04 \mathrm{a}$ \\
DMS (5) & 0,076 & 0,107 & 1,653 & ND & ND & 0,020
\end{tabular}

(1) Médias de duas repetições em triplicata \pm desvio padrão; (2) ATT: Acidez Total Titulável, em \% ácido cítrico; (3) SST: Sólidos Solúveis Totais, em ${ }^{\circ}$ Brix; ${ }^{(4)}$ Aw: Atividade de Água a $20{ }^{\circ} \mathrm{C}$; (5) DMS: Diferença Mínima Significativa; ${ }^{(6)}$ t: tempo. Médias seguidas de letras minúsculas iguais, na mesma coluna, indicam que não houve diferença significativa $(p>0,05)$. Valores em base úmida.

O doce de manga cremoso acrescido de 3\% de farinha de okara apresentou o maior teor de sólidos solúveis, significativamente $(\phi<0,05)$ maior que as amostras controle e acrescida de $1 \%$ de farinha de okara tanto após a fabricação como após 70 dias de armazenamento. De acordo com Resolução Normativa no 9, de 11 de Dezembro de 1978, quanto à consistência, o doce pode ser classificado como cremoso, quando a pasta for homogênea e de consistência mole, não devendo oferecer resistência nem possibilidade de corte, ou em massa, quando a pasta for homogênea e de consistência que possibilite o corte. A resolução ressalta ainda que nos doces cremosos, o teor de sólidos solúveis do produto final não deve ser inferior a $55 \%$. Portanto, todas as amostras elaboradas encontraram-se dentro do padrão estabelecido pela legislação brasileira [6]. Além disso, verificou-se que a adição de $3 \%$ de farinha de okara aumentou a concentração dos sólidos solúveis no produto.

Observou-se em relação ao teor de proteínas que a amostra acrescida de $3 \%$ de farinha de okara obteve maior média $(p<0,05)$, seguida das amostras acrescidas de $1 \%(p<0,05)$ e a sem adição da farinha de okara $(p<0,05)$. Esta variação do teor de proteínas pode ser explicada pelas diferentes porcentagens de okara utilizadas na elaboração do doce de manga cremoso. Segundo Souza et al. [27] a oferta insuficiente de alimentos de baixo custo e ricos em proteína é uma das principais causas de desnutrição nos países em desenvolvimento. Assim, a produção de alimentos protéicos de baixo custo e de qualidade pode ser aumentada com a utilização da soja, em particular, do resíduo de soja (okara), conforme demonstrado nos resultados desse estudo. 
Quanto ao teor de gordura, observou-se que a amostra acrescida de 3\% de farinha de okara apresentou média superior as demais $(\phi<0,05)$. Esta variação se deve às diferentes quantidades de okara utilizada na elaboração do doce de manga, uma vez que o okara possui alto teor lipídico, apresentando em sua constituição ácidos graxos essenciais [28].

A atividade de água expressa o teor de água livre no produto, e variou de 0,848 a 0,863 entre as amostras, sem apresentar diferenças significativas $(\phi>$ $0,05)$ entre as amostras no tempo zero e após 70 dias de armazenamento. Nesta faixa de atividade de água fungos, filamentos e leveduras podem crescer [29], assim, como a adição de farinha de okara não alterou a atividade de água destes produtos e não houve um emprego de conservantes foi necessário o emprego da refrigeração para estabilidade dos produtos.

Pode-se observar que com a adição do subproduto okara existe um aumento na concentração de proteína, lipídeos e fibra bruta. Os doces elaborados sem adição de okara apresentaram o teor de proteína na ordem de $0,28 \%$, os doces elaborados com a adição de 1 e 3\% apresentaram um aumento de 114 e 385\%, respectivamente, para este componente.

\section{Cor objetiva dos doces elaborados}

A análise de cor da formulação convencional e das amostras adicionadas do resíduo da soja estão apresentados na Tabela 2 .

Tabela 2. Cor objetiva (1) do doce de manga cremoso

\begin{tabular}{l|c|c|c}
\hline \multirow{2}{*}{ Amostra } & \multicolumn{3}{c}{ Coordenadas avaliadas (t (6) $\mathbf{0})$} \\
\cline { 2 - 4 } & L* & $\mathbf{a}^{*}$ & $\mathbf{b}^{*}$ \\
\hline \multicolumn{1}{c|}{ Controle } & $30,63 \pm 0,99 \mathrm{a}$ & $10,89 \pm 2,54 \mathrm{a}$ & $21,63 \pm 4,14 \mathrm{a}$ \\
$1 \%$ okara & $32,39 \pm 0,97 \mathrm{a}$ & $9,99 \pm 2,76 \mathrm{a}$ & $20,97 \pm 3,80 \mathrm{a}$ \\
$3 \%$ okara & $33,00 \pm 1,81 \mathrm{a}$ & $9,51 \pm 1,76 \mathrm{a}$ & 3,358 \\
DMS (2) & 4,030 & 1,479 & $\mathrm{a}$
\end{tabular}

\begin{tabular}{l|c|c|c}
\hline \multirow{2}{*}{ Amostra } & \multicolumn{2}{|c}{ Coordenadas avaliadas (t (6) = 70 dias) } \\
\cline { 2 - 4 } & L* & $\mathbf{a}^{*}$ & b* \\
\hline \multicolumn{1}{c|}{ Controle } & $19,24 \pm 4,22 \mathrm{a}$ & $6,56 \pm 0,81 \mathrm{a} \pm 0,29 \mathrm{a}$ \\
1\% okara & $24,06 \pm 1,74 \mathrm{a}$ & $5,61 \pm 1,15 \mathrm{a}$ & $13,31 \pm 2,43 \mathrm{a}$ \\
$3 \%$ okara & $24,52 \pm 2,39 \mathrm{a}$ & $4,82 \pm 0,48 \mathrm{a}$ & $15,98 \pm 1,23 \mathrm{a}$ \\
DMS(2) & 6,839 & 2,215 & 3,719 \\
\hline
\end{tabular}

(1) Médias de duas repetições em triplicata \pm desvio padrão; (2) DMS: Diferença Mínima Significativa; (6) t: tempo. Médias seguidas de letras minúsculas iguais, na mesma coluna, indicam que não houve diferença significativa $(p>0,05)$.

Verificou-se que não houve diferenças das coordenadas $\mathrm{L}^{*}, \mathrm{a}^{*} \mathrm{e} \mathrm{b}^{*}$ entre as três formulações de doce cremoso de manga avaliadas logo após a fabricação e após 70 dias à $10{ }^{\circ} \mathrm{C}(\phi>0,05)$. No entanto, o tratamento controle apresentou cor mais escura (L*), em termos absolutos, do que os tratamentos com adição de farinha de okara, todavia essa diferença não foi significativa $(\phi>0,05)$. Desta forma, pode-se afirmar que a adição de até 3\% de farinha de okara não alterou os parâmetros de cor para o doce analisado. Além disso, verificou-se, em termos absolutos, que após 70 dias de armazenamento os produtos apresentaram uma redução nos valores de L*, $\mathrm{a}^{*}$ e b*. Shi et al. [30] explicam que esse fato é resultante 
da degradação dos carotenoides presentes na fruta e da intensidade dos mecanismos de escurecimento não enzimático, principalmente a caramelização.

Damiani et al. [31] trabalharam com doce de manga variedade Haden e encontraram valores de 28,08; 8,50 e 15,33 para L*, a* e b*, respectivamente. Comparativamente, as formulações deste trabalho apresentaram coloração vermelho ( $a^{*}=9,51$ a 10,89$)$ amarelada $\left(b^{*}=20,59\right.$ a 21,63); fatores como variedade da manga, tempo de cocção, concentração de açúcar podem explicar tais diferenças.

\section{Contagem de Bolores e Leveduras}

A capacidade do açúcar em reduzir a atividade de água e aumentar a pressão osmótica o torna importante no controle da atividade microbiana. Além disso, o tratamento térmico promove a desidratação parcial do produto, além de levar a morte de microorganismos deterioradores e patogênicos, o que aumenta a vida de prateleira dos doces [29]. O grande entrave são as ações posteriores, uma vez que, pode ocorrer contaminação pós-processamento, o que tornaria estes produtos impróprios para o consumo, tendo em vista que fungos, filamentos e leveduras podem crescer em valores de atividade de água abaixo de 0,800 .

Os produtos elaborados apresentaram contagens da ordem de $10^{2}$ UFC. $^{-1}$ de bolores e leveduras (Tabela 3) logo após o processamento e após 70 dias de armazenamento, estando de acordo com os padrões da legislação vigente que estabelece um limite máximo de 1,0 x $10^{4}{\mathrm{UFC} . g^{-1}}^{\text {ou }} 4,0 \log \left(\mathrm{UFC}^{-1}\right)^{-1}{ }^{[21]}$.

Tabela 3. Contagem de bolores e leveduras em amostras de doce de manga cremoso acrescido de farinha de okara

\begin{tabular}{c|c|c}
\hline \multirow{2}{*}{ Amostra } & \multicolumn{2}{|c}{ Bolores e Leveduras log (UFC.g-1) } \\
\cline { 2 - 3 } & $\begin{array}{c}\text { Doce de manga cremoso } \\
\text { (após processamento) }\end{array}$ & $\begin{array}{c}\text { Doce de manga cremoso } \\
\text { (70 dias de armazenamento) }\end{array}$ \\
\hline Controle & $2,96 \pm 0,26$ & $2,70 \pm 0,34$ \\
1\% okara & $2,81 \pm 0,38$ & $2,65 \pm 0,25$ \\
$3 \%$ okara & $2,61 \pm 0,19$ & $2,30 \pm 0,31$ \\
\hline
\end{tabular}

É importante ressaltar que os doces de manga acrescidos de farinha de okara foram elaborados a partir das Boas Práticas de Fabricação, para obtenção de alimentos seguros para o consumo humano. Além disso, não houve adição de nenhum tipo de conservante químico, por isso o emprego da cadeia de frio para aumentar a vida de prateleira dos produtos.

\section{Características sensoriais dos doces elaborados}

Com relação aos atributos avaliados no teste de aceitabilidade e intenção de compra segundo a opinião dos consumidores, os escores são apresentados nas Tabelas 4 e 5, respectivamente.
Verificou-se para o atributo cor que a amostra controle $(7,51 \pm 1,36)$ não diferiu da adicionada de $1 \%$ de okara $(7,20 \pm 1,21)(p>0,05)$, que por sua vez, também não apresentou diferença em relação à adicionada de $3 \%(6,77 \pm 1,80)(p>0,05)$. Para aroma, textura, sabor e impressão global observou-se que a amostra controle $(7,30 \pm 1,27 ; 7,40 \pm 1,18 ; 7,40 \pm 1,48$; $7,36 \pm 1,25$, respectivamente) e a adicionada de $1 \%$ de farinha de okara $(7,22 \pm 1,45 ; 7,29 \pm 1,32 ; 7,14 \pm 1,55$; $7,25 \pm 1,29$, respectivamente) não diferiram entre si $(p$ $>0,05)$, no entanto apresentaram médias superiores em relação ao doce adicionado de 3\% (6,69 \pm 1,26; 6,48 \pm 1,$56 ; 5,87 \pm 1,96 ; 6,18 \pm 1,76$, respectivamente) $(\phi<$ $0,05)$. 
Tabela 4. Análise sensorial de doce de manga cremoso acrescido de diferentes concentrações de farinha de okara

\begin{tabular}{l|c|c|c|c|c}
\hline \multirow{2}{*}{ Amostra } & \multicolumn{5}{|c}{ Atributos avaliados * } \\
\cline { 2 - 6 } & Cor & Aroma & Textura & Sabor & Impressão Global \\
\hline Controle & $7,51 \pm 1,36 \mathrm{a}$ & $7,30 \pm 1,27 \mathrm{a}$ & $7,40 \pm 1,18 \mathrm{a}$ & $7,40 \pm 1,48 \mathrm{a}$ & $7,36 \pm 1,25 \mathrm{a}$ \\
1\% okara & $7,20 \pm 1,21 \mathrm{ab}$ & $7,22 \pm 1,45 \mathrm{a}$ & $7,29 \pm 1,32 \mathrm{a}$ & $7,14 \pm 1,55 \mathrm{a}$ & $7,25 \pm 1,29 \mathrm{a}$ \\
3\% okara & $6,77 \pm 1,80 \mathrm{~b}$ & $6,69 \pm 1,26 \mathrm{~b}$ & $6,48 \pm 1,56 \mathrm{~b}$ & $5,87 \pm 1,96 \mathrm{~b}$ & $6,18 \pm 1,76 \mathrm{~b}$ \\
DMS ** & 0,471 & 0,421 & 0,458 & 0,534 & 0,455 \\
\hline
\end{tabular}

* Notas médias atribuídas pelos julgadores por meio da Escala hedônica. Letras minúsculas (coluna) iguais indicam que não houve diferença significativa entre os atributos avaliados $(p<0,05)$; ** DMS: Diferença Mínima Significativa.

Quanto à intenção de compra, observou-se que as amostras controle e adicionadas de $1 \%$ de okara não diferiram entre si $(p>0,05)$, porém apresentaram médias superiores em relação ao doce adicionado de $3 \%$ de okara $(p<0,05)$.

Tabela 5. Intenção de compra dos consumidores em relação ao doce de manga cremoso acrescido de diferentes concentrações de farinha de okara

\begin{tabular}{l|c}
\hline \multicolumn{1}{c}{ Amostra } & Intenção de Compra * \\
\hline Controle & $4,05 \pm 0,85 \mathrm{a}$ \\
$1 \%$ okara & $3,93 \pm 0,91 \mathrm{a}$ \\
$3 \%$ okara & $3,21 \pm 1,13 \mathrm{~b}$ \\
DMS ** & 0,321
\end{tabular}

* Intenção de compra atribuída pelos julgadores na escala de 1 a 5. Letras minúsculas (coluna) iguais indicam que não houve diferenças significativas entre as amostras $(p<0,05)$; ** DMS: Diferença Mínima Significativa.

Mesmo havendo diferença $(\phi<0,05)$ entre as amostras para os atributos avaliados, todas se enquadraram entre gostei ligeiramente a gostei extremamente. Constatou-se que nenhuma das amostras foi rejeitada pelos julgadores sendo, portanto, um produto agradável e de elevado potencial de mercado. A suplementação de produtos alimentícios com okara foi relatada por Waliszewski et al. [32], que demonstraram que concentrações de até $10 \%$ de okara podem ser adicionadas à Tortillas, alcançando níveis satisfatórios de aceitação.
Genta et al. [33] publicaram um estudo sobre a produção e aceitação de doce de soja, elaborado a partir do subproduto okara e concluíram que amostras contendo concentrações menores de okara apresentaram maior grau de aceitação, como verificado também no presente estudo.

\section{CONCLUSÃO}

Em relação às análises físico-químicas e microbiológicas, verificou-se que as amostras estavam de acordo com os padrões estabelecidos pela legislação brasileira apresentando aumento no teor de gordura e proteína, além disso, as amostras não apresentaram diferença em relação à cor objetiva $\left(L^{*}, a^{*}\right.$ e $\left.b^{*}\right)$. Para todos os atributos sensoriais analisados e intenção de compra não se verificou diferença do tratamento controle para o adicionado de $1 \%$ da farinha de okara. Os doces podem ser considerados produtos atrativos para os consumidores por apresentarem elevadas médias para os atributos sensoriais avaliados. A incorporação de farinha de okara a doces de frutas é uma alternativa viável para a indústria de processamento por apresentar baixo custo de produção, contribuindo para o aproveitamento de resíduos.

\section{AGRADECIMENTOS}

Ao Instituto Federal de Educação, Ciência e Tecnologia do Sudeste de Minas Gerais, campus Rio Pomba (IF Sudeste MG, Rio Pomba) pela oportunidade de realizar este trabalho.

\section{REFERÊNCIAS}


[1] Brandão MCC, Maia GA, Lima DP, Parente EJS, Campello CC, Nassu RT, et al. Análise físico-química, microbiológica e sensorial de frutos de manga submetidos à desidratação osmótico-solar. Rev Bras Frutic. 2003;25(1):3841.

[2] Lima AB, Silva SM, Rocha A, Nascimento LC, Ramalho FS. Conservação pós-colheita de manga 'tommy Atkins' orgânica sob recobrimentos bio-orgânicos. Rev Bras Frutic. 2012;34(3):704-10.

[3] Hortibrasil. A manga no mundo e no Brasil. 2010 [acesso em 01 mar 2013]. Disponível em: http://www.hortibrasil.org.br/jnw/index.php?option=com content\&view $=$ article\&id $=443 \% 3 \mathrm{Aa}$ - manga-no-mundo-eno-brasil\&catid $=64 \% 3$ Afrutas-e-hortalicas-

\section{$\underline{\text { frescas\&Itemid }=82}$}

[4] Santos CNP. Elaboração de um estruturado de polpa de manga (Mangifera indica L. cv Tommy Atkins) parcialmente desidratada por osmose [dissertação]. Campinas: Universidade Estadual de Campinas; 2003. 73 p.

[5] Sugai AY. Processamento descontínuo de purê de manga (mangifera indica Linn.), variedade haden: estudo da viabilidade do produto para pronto consumo [dissertação]. São Paulo: Escola Politécnica da Universidade de São Paulo; 2002. 82 p.

[6] Brasil. Resolução Normativa no 9, de 1978. Câmara Técnica de Alimentos do Conselho Nacional de Saúde. Diário Oficial da União, Brasília, 11 dez. 1978.

[7] Jackix MH. Doces, geléias e frutas em calda. São Paulo: Ícone; 1988.

[8] Associação Brasileira das Indústrias de Alimentação (ABIA). Compêndio de legislação dos alimentos: consolidação das normas e padrões para alimentos. São Paulo: ABIA; 2001.

[9] Damiani C, Almeida ACS, Ferreira J, Asquieri ER, Vilas Boas EVB, Silva FA. Doces de corte formulados com casca de manga. Pesqui Agropecu Trop. 2011;41(3):360-69.

[10] Tfouni SAV, Toledo MCF. Determination of benzoic and sorbic acids in Brazilian food. Food Control. 2002;13(2):117-23.

[11] Jay JM. Microbiologia de alimentos.Porto Alegre: Artmed; 2005.

[12] Su SIT, Yoshida CMP, Contreras-Castillo CJ, Quiñones EM, Venturin AC. Okara, a soymilk industry by-product, as a non-meat protein source in reduced fat beef burgers. Food Sci Technol. 2013;33(Suppl. 1):52-56.
[13] Aplevicz KS, Demiate IM. Análises físico-químicas de pré-misturas de pães de queijo e produção de pães de queijo com adição de okara. Ciênc Agrotec. 2007;31(5):1416-22.

[14] Bowles S. Utilização do subproduto da obtenção de extrato aquoso de soja okara em pães do tipo francês [dissertação]. Ponta Grossa: Universidade Estadual de Ponta Grossa; 2005. 82 p.

[15] Grizotto RK, Andrade JC, Miyagusku L, Yamada EA. Physical, chemical, technological and sensory characteristics of Frankfurter type sausage containing okara flour. Food Sci Technol. 2012;32(3):538-46.

[16] Bowles S, Demiate IM. Caracterização físico-química de okara e aplicação em pães do tipo francês. Ciênc Tecnol Aliment. 2006;26(3):652-59.

[17] Jackson CJC, Dini JP, Lavandier C, Rupasinghe HPV, Faulkner H, Poysa V, et al. Effects of processing on the content and composition of isoflavones during manufacturing of soy beverage and tofu. Process Biochemistry. 2001;37(10):1117-23.

[18] Minim VPR. Análise Sensorial: estudos dos consumidores. Viçosa: Editora UFV; 2010.

[19] Instituto Adolfo Lutz. Métodos químicos e físicos para análise de alimentos. São Paulo: Editora do IAL; 2008.

[20] Brasil. Ministério da Agricultura, Pecuária e Abastecimento. Departamento de Inspeção de Produtos de Origem Animal. Instrução Normativa no 62, de 26 de agosto de 2003. Métodos analíticos oficiais para análises microbiológicas para controle de produtos de origem animal e água. Diário Oficial da União, Brasília, 18 set. 2003. Seção 1, p. 14.

[21] Brasil. Agência Nacional de Vigilância Sanitária. Resolução RDC no 12, de 2 de janeiro de 2001. Regulamento técnico sobre os padrões microbiológicos para alimentos. Diário Oficial da União, Brasilia, 10 jan. 2001. Seção 1, p. 45.

[22] Cavalheiro SFL, Tininis CRCS, Tavano OL, Custódio MF, Rossi EA, Cardello HMAB. Biscoito sabor chocolate do resíduo de soja "okara": teste de afetivo com crianças em idade pré-escolar. Alimentos Nutrição, São Paulo. 2001;12(1):151-62.

[23] Cantuária CM, Ribeiro SCA, Ribeiro CFA, Park KJ, Araújo EAF. Perfil sensorial de pães de forma enriquecidos com okara. Revista Brasileira de Produtos Agroindustriais. 2008;10(2):111-120.

[24] Hasler CM. Functional foods: their role in disease prevention and health promotion. Food Technol. 1998;52(11):63-70. 
[25] Cocozza F. Maturação e conservação de manga Tommy Atkins submetida à aplicação pós colheita de 1metilciclopropeno [tese]. Campinas: Faculdade de Engenharia Agrícola; 2003. 198 p.

[26] Brasil. Agência Nacional de Vigilância Sanitária (ANVISA). Resolução RDC no 272, de 22 de setembro de 2005. Regulamento técnico para produtos de vegetais, produtos de frutas e cogumelos comestíveis. Diário Oficial da União, Brasília, 23 de set. 2005. Seção 1, p. 374.

[27] Souza G, Valle JLE, Moreno I. Efeitos dos componentes da soja e seus derivados na alimentação humana. Bol. SBCTA. 2000;34(2):61-69.

[28] Rosenthal A, Deliza R, Cabral LMC, Cabral LC, Farias CAA, Domingues AM. Effect of enzymatic treatment and filtration on sensory characteristics and physical stability of soymilk. Food Control. 2003;14(3):187-92.
[29] Araújo JMA. Química de alimentos: teoria e prática. Viçosa: Editora UFV; 2001.

[30] Shi J, Dai Y, Kakuda Y, Mittal G, Sue SJ. Effect of heating and exposure to light on the stability of lycopene in tomato purée. Food Control. 2008;19(5):514-20.

[31] Damiani C, Vilas Boas EVB, Soares Júnior M, Caliari M, Paula ML, Pereira EP, et al. Análise física, sensorial e microbiológica de geléias de manga formuladas com diferentes níveis de cascas em substituição à polpa. Ciênc Rural. 2008;38(5):1418-23.

[32] Waliszewski KN, Pardio V, Carreon E. Physicochemical and Sensory Properties of Corn Tortillas Made from Nixtamalized Corn Flour Fortified with Spent Soymilk Residue (okara). J Food Sci. 2002;67(8):3194-97.

[33] Genta HD, Genta ML, Álvarez, NV, Santana MS. Production and acceptance of a soy candy. J Food Eng. 2002;53(2):199-202. 